\title{
Comparison between Trans-Radial Versus Trans-Femoral Arterial Access in Primary Percutaneous Coronary Intervention
}

\author{
K.A.EIrabbat, M.A.Hamoda, A.E.Elnagar, A.Y.Nammour and M.A.Mohamed
}

Cardiology, Dept., Faculty of Medicine, Benha University

E-mail:Mohamed11@gmail.com

\begin{abstract}
Background: Coronary catheterization is usually performed via the trans-femoral approach. Trans-radial access offers advantages in comparison with trans-femoral access, especially under conditions of aggressive anticoagulation and antiplatelet treatment in which bleeding complications at the femoral puncture site can result in increased morbidity and duration of hospitalization, Aim and objectives: the aim of the study was to compare 30 days outcome between radial and femoral approaches in patients presenting with ST-segment elevation myocardial infarction (STEMI) and undergoing primary percutaneous coronary intervention (PCI), Subjects and methods: this was a Prospective, randomized, open-label, double-arm, single center study, that was conducted on 120 STEMI patients; subdivided randomly into 2 groups. Group A (60 patients) had Primary PCI through femoral access; Group B (60 patients) had Primary PCI through radial access, Results: Hospitalization time in group (I) was ranged between 3-8 days with mean \pm S.D. $5.35 \pm 1.686$ days while in group (II) was ranged between $5-10$ days with mean \pm S.D. $7.32 \pm 1.751$ days. There were statistically significant differences between groups, and Complications in group (I) showed that $9(15.0 \%)$ had access site complication, 4(6.7\%) had hematoma, 2(3.3\%) had Pseudoaneurysm and 7(11.7\%) had Radial artery spasm while in group (II) 6(10.0\%) had Access site complication. There was no statistically significant difference between groups, Conclusion: trans-radial approach is an equally effective approach as trans-femoral approach similar success and complication rates.
\end{abstract}

Keywords: Trans-radial, Trans-femoral, STEMI, PCI, Coronary catheterization.

\section{Introduction}

A growing A rising amount of data supports the use of Trans radial percutaneous procedure as the preferred entry point for the treatment of individuals with myocardial high ST-segment infarction (STEMI). Transradial intervention in the STEMI population has historically been prevented owing to concerns about protracted procedure time, longer door-to-balloon time, increased crossover rates, and the amount of transradial access experience needed compared to transfemoral access. However, knowledge of the mortality significance of periprocedural bleeding in patients with acute heart syndrome in recent years has attracted attention in the use of TRI as a proven approach for bleeding reduction.

The transradial intervention has similarly shown reduced periprocedural bleeding as well as a decreased mortality compared to transfemoral access among the STEMI population[1] by registry data, meta-analyzes, and randomised control studies.

Three particular tests; RIVAL (Radial versus Femoral Access to Coronary Invasion), STEMIRADIAL (ST Elevation Myocardial Infarction Treated in Radial or Femoral Approaches) and RIFLESTEACS (Radial Versus Femoral Randomized Investigation in ST Elevation Acute coronary syndrome); all continuously shown lower levels of bleeding and vascular complications with the transradial approach; [2]

Bleeding is an independent predictor for bad longterm results, including mortality, predisposes patients to transfusions and reduces the capacity to give cardiovascular post-procedural anticoagulation[3]. Bleeding
Bleeding is an important indicator of poorer outcomes in people with acute coronary syndrome.

Access site issues are a substantial cause of bleeding for those revascularization patients, in particular when femoral access is employed (Cardiac et al., 2013). Observational studies have also shown a decreased incidence of radial mortality and myocardial infarction than femoral access, however this analysis is hampered by possible confusing factors[4].

Complications with the access site are a substantial cause of bleeding in patients undergoing revascularization, particularly when using femoral access. Observatory studies have also revealed a decreased incidence of radial mortality and myocardial infarction than femoral access, however this is restricted because to possible confusing factors[4].

This research intends to evaluate 30 day outcomes between radial and femoral methods in individuals with ST-segment STEMI and primary percutaneous infarction. (PCI).

\section{Patients and methods}

This was a prospective, randomised open-label, double-arm, single-centre trial. After being diagnosed as acute STEMI, patients were deemed admissible and primary PCI was planned as their first reperfusional procedure, which had been carried out within 12 hours of the beginning of symptoms.

\section{Excluded patients}

The Patients were eliminated when they had one; cardiogenic shock; pre-existing surgery for coronary artery bypassing, significant vascular disease in the periphery precluding a femoral approach. Abnormal Allen's test, INR $>2$; mechanical problems. 
The research was authorised and all subjects received written informed permission from relevant institutional regulatory authorities and ethical committees.

According to a random table produced by the statistician who is not engaged in the operation or patient care, patients consenting had been randomised at 1:1. Randomization was done while the patient was in the catheterization laboratory and before vascular access was obtained. The statistician was notified of the requirement for a random allocation by the study team. The statistician then gives the team the patient's telephone allocation.

The sample size needed for identifying the statistically substantial variability of the primary endpoint in the two groups was estimated in the number of patients included in this study; first Group patients with primary transfemoral PCI, second Group patients with primary transradial PCI, based on netclinical adverse event results, at 30 days, in the radial group were 13.6 percent and in the femoral group.

- Group A: primary PCI via femoral access. • Group B: primary PCI via radial access.

All participating cardiologists had a significant amount of intervention (more than 75 elective PCIs per year with at least half of elective cases through radial access for a minimum of 50 percent of the cases through radial Access).

All patients were randomised to 1:1 radial or femoral access prior to arterial access. A physician assessed the bi-femoral and radial pulses; modified Allen's test was done on both hands to confirm the ulnar collateral circulation. Procedural anticoagulation was accomplished with unfractionated heparin bolus pre-administered at a dosage of $60 \mathrm{UI} / \mathrm{kg}$ supplemented throughout the operation to maintain a 250 second activated clotting time. The operator decided on additional antithrombotic periprocedural medications (e.g. Glycoprotein IIb/IIIa inhibitors).

- Radial Access Group Technical Aspects: All cases were performed on the right radial side; local anaesthetic had been performed by $0.5-1-\mathrm{ml}$ Lidocaine 2 percent of subcutaneous infiltration. Routine vasodilator employs nitroglycerine $(100 \mathrm{mcg})$ and/or verapamil cocktail following sheath insertion $(2.5 \mathrm{mg})$. The bare needle for radial artery puncture was then utilised for advancing catheters through the arm through to the coronary ostia with a $10 \mathrm{~cm}$ hydrophilic sheath size of 6 fr. standard J-shaped wire of 0.035 inch $(0.889-\mathrm{mm})$ was employed. Hydrophilic wire (Glide wire, Terumo, Tokyo, Japan) was utilised for radial or brachial artery tortuosity or looping. The diagnostic catheter is 5 or 6-F (Judkins left 3.5 and Judkin right 4.0 and catheters guiding 6-F). To get the "air-bag" (TR band, Terumo) nostasis bracelet becomes the most often used hamostasis device and is scheduled for release within 90 minutes.

- All anticoagulants were terminated at the conclusion of the surgery unless clinically contraindicated, whereas glycoprotein IIb/IIIa inhibitor boluses were followed by 18-24 hours of infusion 220 .

- Acetylsalicylic acid with a charge dosage of Clopidogrel (300 to $600 \mathrm{mg}$ ) or Ticagrelor $180 \mathrm{mg}$ were pretreated to all patients and are reported for a double antiplatelet treatment period of 12 months.

- According to the view of the main operator, technical methods (for example thrombectomy, direct stenting) will be determined.

Result and follow-up patients:

- Primary endpoint: was a composite of major adverse heard events and cerebrovascular events (MACCE), which were defined as heart or non-cardiac mortality, reinfarction and acute coronary syndrome rehospitalization, target lesion, revascularization and stroke. Net clinical adverse events (NACEs) have been characterised as mortality compound, myocardial infarction (MI), stroke, and significant bleeding/vascular complications.

- Secondary endpoint: cardiac mortality, acute coronary syndrome rehospitalization, target-lesion revascularization, stroke, blueberries and hospitalisation;

- Patients were examined on a regular basis for results during inpatient and outpatient visits. Visits are arranged for 30 days following surgery.

\subsection{Statistical analysis}

The data was gathered, tabulated, statistically evaluated with the application of the following statistics using IBM personal computers with Statistical Package of Social Science (SPSS) version 20 and Epi Info 2000 programmes. There have been two forms of statistical analysis: Descriptive statistics: In form of medium (X), standard deviation (SD), range and qualitative data, numbers (No) and percentages are provided in quantitative figures ( percent ). Statistics analytical: Student t-test $(\mathrm{t})$ : was used to compare two groups with one way variable quantitative parameter. Anova test(f): has been used to compare quantitative parameter variables for many groups. Chi-squared test (Ś2): was employed for the examination of the combination of two qualitative variables. The exact test of Fisher (FET): for two x 2 tables, the cell count predicted to exceed 25 percent of instances was lower than 5. Mann Whitney test (U): utilised in two groups with non-parameter quantitative variables for comparison. Kruskal-Wallis test (KW): was used to compare non-distributed groups Variables.

\section{Results}

Age in group (I) was ranged between 45-89 years with mean \pm S.D. $66.55 \pm 9.844$ years while in group (II) was ranged between $40-87$ years with mean \pm S.D. $64.88 \pm 11.152$ years. There was no statistically significant differences between groups where $\mathrm{P}=0.387$ Table (1). 
Table (1) Comparison between two groups as regard to patient's age (years)

\begin{tabular}{llll}
\hline Age & $\begin{array}{l}\text { Group (I) } \\
(\mathbf{n = 6 0 )}\end{array}$ & $\begin{array}{l}\text { Group (II) } \\
(\mathbf{n = 6 0 )}\end{array}$ & P Value \\
\hline Min.-Max. & $45-89$ & $40-87$ & 0.387 \\
Mean \pm S.D & $66.55 \pm 9.844$ & $64.88 \pm 11.152$ & \\
\hline
\end{tabular}

Gender in group (I) show that $45(75 \%)$ were male and $15(25 \%)$ were female while in group (II) $48(80 \%)$ were male and $12(20 \%)$ were female. There was no statistically significant differences between groups where $\mathrm{P}=0.662$ Table(2).

Table (2): Comparison between two groups as regard to patient's gender

\begin{tabular}{lccccc}
\hline Gender & \multicolumn{2}{c}{$\begin{array}{c}\text { Group (I) } \\
(\mathbf{n = 6 0 )}\end{array}$} & \multicolumn{2}{c}{$\begin{array}{c}\text { Group (II) } \\
(\mathbf{n = 6 0 )}\end{array}$} & P Value \\
& No. & $\%$ & No. & $\%$ & \\
\hline Male & 45 & 75 & 48 & 80 & 0.662 \\
Female & 15 & 25 & 12 & 20 & \\
Total & 60 & 100 & 60 & 100 & \\
\hline
\end{tabular}

Total length of stents used in group (I) was ranged between $15-66 \mathrm{~mm}$ with mean \pm S.D. $40.78 \pm 15.476 \mathrm{~mm}$ while in group (II) was ranged between $21-67 \mathrm{~mm}$ with mean \pm S.D. $46.52 \pm 14.979 \mathrm{~mm}$. There were statistically significant differences between groups where $\mathrm{P}=0.039$ Table (3).

Table (3) Comparison between two groups as regard to patient's Total length of stents used.

\begin{tabular}{llll}
\hline Total length of stents used & $\begin{array}{l}\text { Group }(\mathbf{I}) \\
(\mathbf{n = 6 0})\end{array}$ & $\begin{array}{l}\text { Group (II) } \\
(\mathbf{n = 6 0 )}\end{array}$ & P Value \\
\hline Min.-Max. & $15-66$ & $21-67$ & $0.039^{*}$ \\
Mean+ S.D & $40.78 \pm 15.476$ & $46.52 \pm 14.979$ & \\
\hline
\end{tabular}

Total fluoroscopy time in group (I) was ranged between 15-40 min with mean \pm S.D. 28.67 \pm 7.471 min while in group (II) was ranged between 10-45 min with mean \pm S.D. $31.08 \pm 10.213 \mathrm{~min}$. There were no statistically significant differences between groups where $\mathrm{P}=0.133$ Table (4).

Table (4) Comparison between two groups as regard to patient's Total fluoroscopy time.

\begin{tabular}{lccc}
\hline Total fluoroscopy time & $\begin{array}{c}\text { Group (I) } \\
(\mathbf{n = 6 0 )}\end{array}$ & $\begin{array}{c}\text { Group (II) } \\
(\mathbf{n = 6 0 )}\end{array}$ & P Value \\
\hline Min.-Max. & $15-40$ & $10-45$ & $0.133^{*}$ \\
Mean \pm S.D & $28.67 \pm 7.471$ & $31.08 \pm 10.213$ & \\
\hline
\end{tabular}

Total procedure time in group (I) was ranged between 30-90 min with mean \pm S.D. 61.00 \pm 18.199 min while in group (II) was ranged between $45-90 \mathrm{~min}$ with mean \pm S.D. $72.58 \pm 13.639 \mathrm{~min}$. There were statistically significant differences between groups where $\mathrm{P}<0.001$ Table (5).

Table (5) Comparison between two groups as regard to patient's Total procedure time.

\begin{tabular}{lccc}
\hline Total procedure time & $\begin{array}{c}\text { Group (I) } \\
(\mathbf{n = 6 0})\end{array}$ & $\begin{array}{c}\text { Group (II) } \\
(\mathbf{n = 6 0})\end{array}$ & $\begin{array}{c}\text { P } \\
\text { Value }\end{array}$ \\
\hline Min.-Max. & $30-90$ & $45-90$ & $<0.001^{*}$ \\
Mean \pm S.D & $61.00 \pm 18.199$ & $72.58 \pm 13.639$ & \\
\hline
\end{tabular}

Procedural success in group (I) show that 50(83.3\%) had Procedural success while in group (II) $48(80.0 \%)$ had Procedural success. There was no statistically significant differences between groups where $\mathrm{P}=0.814$ Table (6).

Table (6) Comparison between two groups as regard to patient's Procedural success.

\begin{tabular}{lccccc}
\hline Procedural success & \multicolumn{2}{c}{$\begin{array}{c}\text { Group (I) } \\
\text { (N=60) }\end{array}$} & \multicolumn{2}{c}{$\begin{array}{c}\text { Group (II) } \\
\text { (N=60) }\end{array}$} & P Value \\
& No. & $\%$ & No. & $\%$ & \\
\hline No & 10 & 16.7 & 12 & 20.0 & 0.814 \\
Yes & 50 & 83.3 & 48 & 80.0 & \\
Total & 60 & 100 & 60 & 100 & \\
\hline
\end{tabular}

Hospitalization time in group (I) was ranged between 3-8 days with mean \pm S.D. 5.35 \pm 1.686 days while in group (II) was ranged between $5-10$ days with mean \pm S.D. $7.32 \pm 1.751$ days. There were statistically significant differences between groups where $\mathrm{P}=0.001$ Table (7). 
Table (7) Comparison between two groups as regard to patient's Hospitalization time.

\begin{tabular}{llll}
\hline Hospitalization time(days) & $\begin{array}{l}\text { Group (I) } \\
(\mathbf{n = 6 0})\end{array}$ & $\begin{array}{l}\text { Group (II) } \\
(\mathbf{n = 6 0 )}\end{array}$ & P Value \\
\hline Min.-Max. & $3-8$ & $5-10$ & $<0.001^{*}$ \\
Mean \pm S.D & $5.35 \pm 1.686$ & $7.32 \pm 1.751$ & \\
\hline
\end{tabular}

Complications in group (I) show that 9(15.0\%) had Access site complication, 4(6.7\%) had hematoma, 2(3.3\%) had Pseudoaneurysm and 7(11.7\%) had Radial artery spasm while in group (II) 6(10.0\%) had Access site complication. There was no statistically significant differences between groups Fig. (1).

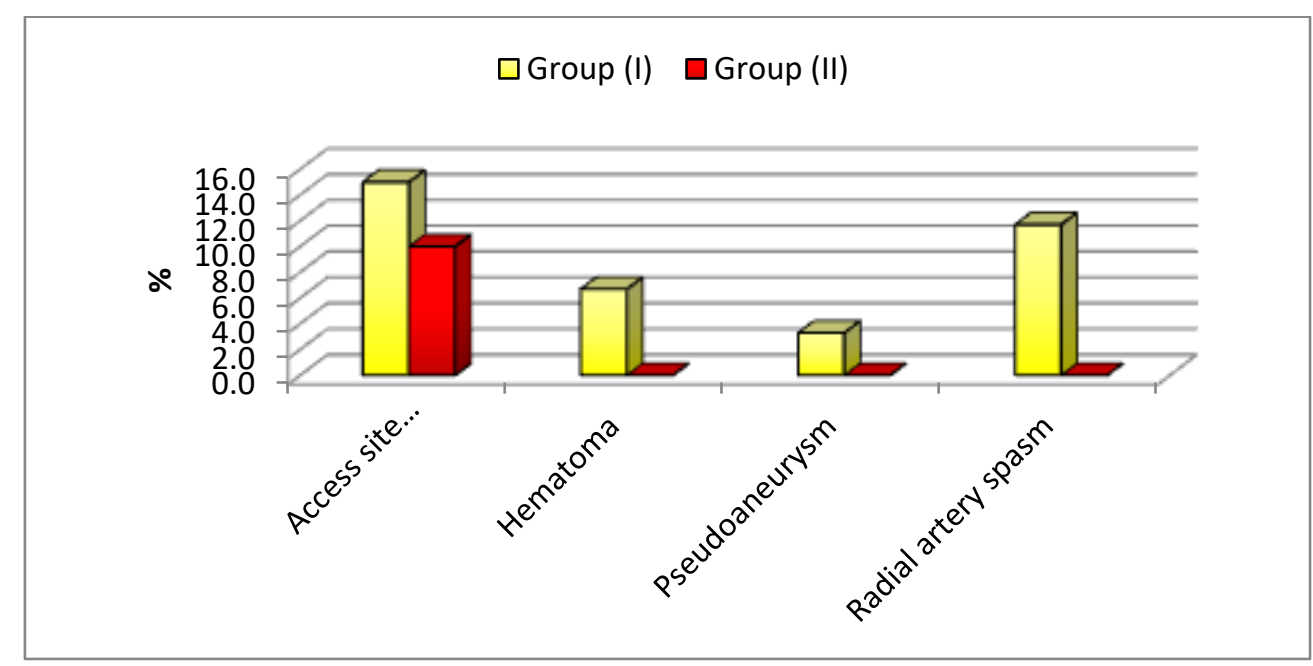

Fig. (1) Comparison between two groups as regard to patient's Complications.

\section{Discussion}

In Our research, group (I) hospitalisation time ranging from 3-8 days, mean \pm S.D. $5.35 \pm 1.686$ days, whereas group hospitalisation time (II) ranges from 510 days, mean \pm S.D. $7.32 \pm 1.751$ days. Statistically significant differences existed between $\mathrm{P}=0,001$ groups.

In the Jang et al. trial, [5] compared with transfemoral approaches. The duration of hospital stay with transradial access was less than that for transfemoral access, and the mean weighted difference was 2.23 days $(95 \% \mathrm{CI}-3.32-1.14, \mathrm{p}<0.001)$. This is at odds with our findings.

In the Bakker et al. study[6] there was no significant difference in hospital stay for both groups.

In this research, group (I) hospital mortality showed that all patients survived whereas just one patient died in group (II). There were no statistically significant differences across $\mathrm{P}=1,000$ groups. $\mathrm{CABG}$ urgent group (I) shows that $2(3.3 \%)$ are in need of CABG urgent, whereas group (II) $4(6.7 \%)$ is in need of CABG Urgent. There were no statistically significant differences across $\mathrm{P}=0.679$ groups.

As regards complications of group (I), there was a complication of Access site 9(15.0 percent), 4(6.7 percent), a pseudoaneurysm 2(3.3 percent), whereas in group (II) 6(10.0 percent) the complication of Access site and 7(11.7 percent) the complication were Radial Artery Spasm. The difference between groups was not statistically significant.
In the Bakker et al. trial [6], the main adverse heart and brain events occurred in hospitals at $2,0 \%$ in fTRA and $2.9 \%$ in TFA $(\mathrm{P}=0,40)$. Major site bleeding occurred in fTRA at $0.3 \%$ and TFA at $0.5 \%(\mathrm{P}=0.66)$ of $0.3 \%$. No significant difference was noticed between the two groups.

Chiarito et al.,[7] stated that 31 trials were found (30,096 patients, PCI performed in 21,225 patients). Radials were significantly reduced in serious bleeding compared with the femoral access (OR 0.53, 95\% CI $0.42-0.66, \mathrm{I} 2=3.3 \%$ ) The conclusions were similar irrespective of clinical features or whether coronary angiography with or without PCI was done. In previous research published and in individuals with chronic coronary syndrome, the advantage of radial access was dramatically enhanced. The stroke risk was similar across groups (OR 1.11, CI 95\% 0.76-1.64, I2 = 0 percent) and MI (OR 0.90, CI 95\% 0.79-1.04, I2 = 0 percent). The risk of death and vascular problems with radial than femoral access was much lower.

Also, Mamas et al., [8] indicated that the TRA is linked with lower 30-day mortality (hazard ratio [HR]: $0.71,95 \%$ confidence in hospitals $[\mathrm{CI}]: 0.52$ to $0.97 ; \mathrm{p}$ $<0,05$ ) and MACCE (HR: 0,73; 95\% CI: 0,57 to,93; p $<0,05$ ), major bleeding (HR: 0,37; 95\% CI: 0,18 to $0,74, \mathrm{p}<0,01)$ as well as site access complications (HR: 0,$38 ; 95 \%$ CI: 0,18 to 0,$74 ; \mathrm{p}<0,01$ ).

In the Le May et al. study[9], TRA is superior than TFA in reduction of net clinical adverse events (NACE) by a decrease in blood flow and mortality. 
However, Jang et al.[5] have shown a considerable reduction in the number of major adverse cardiac events involved in a trans-radial approach (Oodds ratio [OR] 0.56, 95\% confidence interval (OR [CI] 0.44-0.72, p<0.001), mortality (OR 0.55, 95\% CI $0.42-0.72, \mathrm{p}<0.001$ ) and major bleeding (OR 0.32, 95\% CI $0.22-0.48, \quad \mathrm{p}<0.001)$, as compared to transfemoral approaches. There was a shorter transradial hospital stay, with a weighted mean difference in transfemoral access of 2,23 days (95 percent CI - 3,32$1,14, \mathrm{p}<0,001)$. The fluoroscopic times, door-toballoon times and procedural times between both access lines were not differentiated $(\mathrm{p}=0.09, \mathrm{p}=0.38$, $\mathrm{p}=0.82$, respectively). The rate of cross-site access with trans radial access appeared to be greater $(\mathrm{p}=0.06)$.

The Dall'Orto et al.[10] research found that deaths in hospitals $(5.8 \%$ against $5.5 \% ; \mathrm{p}=0.81)$, myocardial infarction $(1.4 \%$ against $0 ; \mathrm{p}=0.76)$, and urgent PCI were comparable across groups $(1.4 \%$ vs $0 ; p=0.76)$. In the women's groups, there was one incidence of subacute stent thrombosis with the accompanying increase in myocardial infarction and immediate percutaneous reaction in the ST sector. There was only one incidence of serious bleeding among women with respect to the incidence of bleeding.

Our findings also coincides with the RADIAMI II in which the prevalence of major adverse cardiac events (MACE) across groups did not vary significantly: 2.1 percent for the TRA group compared to 1.7 percent for the TFA group. No significant difference in access site complication and hematoma was also noted Formation.

\section{Conclusion}

Trans-radial method is an equally successful strategy with comparable successes and complications in the cross-femoral technique, along with extra patient advantages from comfort, preferential treatment and lower healthcare costs.

\section{References}

[1] S.V Rao, M.G.Cohen, D.E.Kandzari, O.F.Bertrand, and I.C.Gilchrist, "The transradial approach to percutaneous coronary intervention: historical perspective, current concepts, and future directions," J.Am.Coll.Cardiol., vol. 55, pp. 21872195, 2010.

[2] P. Agostoni , "Radial versus femoral approach for percutaneous coronary diagnostic and interventional procedures: systematic overview and meta-analysis of randomized trials," J. Am. Coll. Cardiol., vol. 44, pp. 349-356, 2004.

[3] W.J.Cantor, "Radial versus femoral access for emergent percutaneous coronary intervention with adjunct glycoprotein IIb/IIIa inhibition in acute myocardial infarction-the RADIAL-AMI pilot randomized trial," Am. Heart J., vol. 150, pp. 543549, 2005.

[4] R. G. Carere, "Suture closure of femoral arterial puncture sites after coronary angioplasty followed by same-day discharge," Am. Heart J., vol. 139, pp. 52-58, 2000.

[5] J.S.Jang, "The transradial versus the transfemoral approach for primary percutaneous coronary intervention in patients with acute myocardial infarction: a systematic review and meta-analysis," EuroIntervention, vol. 8, pp. 501-510, 2012.

[6] E.J.Bakker, "Fully transradial versus transfemoral approach for percutaneous intervention of coronary chronic total occlusions applying the hybrid algorithm: insights from RECHARGE registry," Circ. Cardiovasc. Interv., vol. 10, p. e005255, 2017.

[7] M.Chiarito , "Radial versus femoral access for coronary interventions: An updated systematic review and meta-analysis of randomized trials," Catheter. Cardiovasc. Interv., vol. 5, pp. 23-31, 2021.

[8] M.A.Mamas , "British Cardiovascular Intervention Society and the National Institute for Cardiovascular Outcomes Research," Influ. Arter. access site Sel. outcomes Prim. percutaneous Coron. Interv. are results randomized trials achievable Clin. Pract., vol. 6, pp. 698-706, 2013.

[9] M.R.Le May, K.Singh, and G.A.Wells, "Efficacy of radial versus femoral access in the acute coronary syndrome: is it the operator or the operation that matters?," JACC Cardiovasc. Interv., vol. 8, pp. 1405-1409, 2015.

[10]C.C.Dall'Orto , “Comparison of Percutaneous Coronary Intervention Outcomes in Men and Women Using the Transradial Approach in Acute Coronary Syndrome," Rev. Bras. Cardiol. Invasiva, vol. 22, pp. 16-22, 2014. 